Proceeding Paper

\title{
Removal of Manganese Using Polymer Gel Composites †
}

\author{
Syed Ragib Safi and Takehiko Gotoh *
}

Citation: Safi, S.R.; Gotoh, T. Removal of Manganese Using Polymer Gel Composites. Mater. Proc. 2021, 4, 68. https://doi. org/10.3390/IOCN2020-07846

Academic Editors: Ana María Díez-Pascual, Antonio Di Bartolomeo and Guanying Chen

\section{Published: 11 November 2020}

Publisher's Note: MDPI stays neutral with regard to jurisdictional claims in published maps and institutional affiliations.

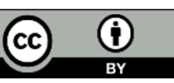

Copyright: $₫ 2020$ by the authors. Licensee MDPI, Basel, Switzerland. This article is an open access article distributed under the terms and conditions of the Creative Commons Attribution (CC BY) license (http://creativecommons.org/licenses/by/4.0/).
Department of Chemical Engineering, Hiroshima University, 1-4-1 Kagamiyama, Higashi, Hiroshima 739-8527, Japan; d196289@hiroshima-u.ac.jp

* Correspondence: tgoto@hiroshima-u.ac.jp; Tel.: +81-82-424-7720

+ Presented at the 2nd International Online-Conference on Nanomaterials, 15-30 November 2020; Available online: https://iocn2020.sciforum.net/.

\begin{abstract}
Manganese is the biggest concern in Bangladesh after Arsenic, as almost $50 \%$ area contains groundwater with Mn concentrations greater than the WHO drinking water guidelines. The previous studies suggested that $\gamma$-FeOOH could remove Mn effectively from water. However, those studies were conducted at higher $\mathrm{pH}$ levels and not in natural conditions. Additionally, the practical applicability of the Mn removal methods was not discussed. Moreover, additional separation processes required to separate the adsorbents and precipitations are not environmentally friendly. Therefore, to improve the Mn removal efficiency at natural $\mathrm{pH}$ levels and other natural water conditions, we examined Mn removal by adsorption technology using polymer gel composites. The gel composites were a cationic gel composite, $N, N^{\prime}$-dimethylamino propylacrylamide, methyl chloride quaternary (DMAPAAQ), loaded with iron hydroxide (DMAPAAQ + FeOOH), and a non-ionic gel composite, $N, N^{\prime}$-Dimethylacrylamide (DMAA), loaded with iron hydroxide (DMAA + FeOOH). DMAPAAQ + FeOOH gel contains $62.01 \mathrm{wt} \%$ of $\gamma$-FeOOH in its polymer structures because of the unique preparation method and this gel showed better As removal efficiency than the other adsorbents at natural conditions ensuring its environmental friendliness. Our results suggest that the cationic gel composite, DMAPAAQ + FeOOH, removed Mn more than that of DMAA + FeOOH because the content of $\gamma$-FeOOH particles was higher in the gel structure of DMAPAAQ + FeOOH. Besides the polymer component of DMAPAAQ + FeOOH contributing to the adsorption of Mn, it carried the higher amount of $\gamma$-FeOOH components, which helped to further increase Mn removal. Our results also suggested that the presence of As did not have any effect on the adsorption of $\mathrm{Mn}$ with DMAPAAQ + FeOOH gel composite because the polymeric component (DMAPAAQ) adsorbed As and the $\gamma$-FeOOH particles adsorbed $\mathrm{Mn}$, which provides the basis for simultaneous adsorption of As and $\mathrm{Mn}$. This research is a base for the simultaneous removal of harmful components such as As, Mn, Cr, Cd, and more.
\end{abstract}

Keywords: polymer gel; arsenic; manganese; water; adsorption; cationic gel

\section{Introduction}

Manganese $(\mathrm{Mn})$ is a known mutagen. The accumulation of Mn may cause hepatic encephalopathy. Consumption of Mn through drinking water may cause neurologic damage. WHO set a limit of $0.5 \mathrm{mg} / \mathrm{L}$ of $\mathrm{Mn}$ in drinking water because of the neurotoxic and other effects among humans and other animals in Japan and Greece [1].

After Arsenic (As), Mn is one of the most commonly found components in most of the rivers and groundwater in Bangladesh [2]. Almost 50\% area of Bangladesh contains groundwater with Mn concentrations greater than the World Health Organization (WHO) health-based drinking water guidelines. The maximum concentration of Mn was found at $2.0 \mathrm{mg} / \mathrm{L}$ in Bangladeshi groundwater. Whereas, WHO approves a maximum of $0.5 \mathrm{mg} / \mathrm{L}$ of $\mathrm{Mn}$ in the drinking water. In almost 35\% of the samples collected by Frisbie et al., WHO drinking water guidelines exceeded for both As and Mn [1]. Besides, As and 
Mn were among the most critical pollutants for drinking water in the South African region [3]. Hence, simultaneous removal of As and Mn needs to be studied.

There are many studies on the removal of As and a few studies on the removal of $\mathrm{Mn}$. However, the study on simultaneous removal of As and Mn is rare because it is hard to remove anionic and cationic components with the same adsorbent. Hence, for the first time, we conducted a study on the removal of As and Mn simultaneously with the same adsorbent.

Previously, we reported the effective removal As from groundwater with our novel adsorbent, $N, N^{\prime}$-dimethylamino propylacrylamide, methyl chloride quaternary (DMAPAAQ), loaded with iron hydroxide (DMAPAAQ + FeOOH) [4-6]. The type of $\mathrm{FeOOH}$ in the polymer structure of DMAPAAQ + FeOOH gel was $\gamma$-FeOOH [6]. A study by Sung et al. (1981) reported that $\gamma-\mathrm{FeOOH}$ removed Mn effectively. However, the $\mathrm{Mn}$ removal efficiency was achieved in the controlled (higher) $\mathrm{pH}$ values. Additionally, the performance of $\gamma-\mathrm{FeOOH}$ in removing $\mathrm{Mn}$ at the natural water conditions was not discussed. In this research, we experimented with the adsorptive removal of Mn using our previously developed gel, DMAPAAQ + FeOOH. Moreover, we compared the removal efficiency of DMAPAAQ + FeOOH gel with non-ionic gel and non-ionic gel composite, in removing Mn. Lastly, we conducted the simultaneous adsorption of As and Mn. The objectives of this research were to effectively remove two of the most harmful elements in Bangladeshi water, As and Mn, simultaneously and at the natural water conditions.

\section{Materials and Methods}

\subsection{Materials}

The monomer, $N, N^{\prime}$-dimethylamino propylacrylamide, methyl chloride quaternary (DMAPAAQ) (75\% in $\mathrm{H}_{2} \mathrm{O}$ ) was supplied by KJ Chemicals Corporation, Japan. The crosslinker, $N, N^{\prime}$-methylene bisacrylamide (MBAA), and the arsenic (III) source, sodium (meta) arsenite were purchased from Sigma-Aldrich, St. Louis, MO, USA. The accelerator sodium sulfite $\left(\mathrm{Na}_{2} \mathrm{SO}_{3}\right)$, the manganese source, $\mathrm{MnSO}_{4} .5 \mathrm{H}_{2} \mathrm{O}$, the arsenic $(\mathrm{V})$ source, disodium hydrogen arsenate heptahydrate $\left(\mathrm{Na}_{2} \mathrm{HAsO}_{4} .7 \mathrm{H}_{2} 0\right)$, and ferric chloride $\left(\mathrm{FeCl}_{3}\right)$ were purchased from Nacalai Tesque, Inc., Kyoto, Japan. Sodium hydroxide $(\mathrm{NaOH})$ was purchased from Kishida Chemicals Corporation, Osaka, Japan. The monomers, N,N'-dimethyl acrylamide (DMAA) and 2-acrylamido 2-methyl propane sulfonic acid (AMPS) were purchased from TCI, Tokyo, Japan. The initiator, ammonium peroxodisulfate (APS) was purchased from Kanto Chemical Co. Inc., Tokyo, Japan.

\subsection{Synthesis of the Polymer Gels and Composites}

The polymer gels, DMAPAAQ, DMAPAAQ + FeOOH were prepared by the freeradical polymerization method, as described in our previous studies [4-6]. The amount of crosslinker, initiator, and accelerator was the same in the compositions of the DMAPAAQ, DMAPAAQ + FeOOH, and DMAA + FeOOH. In the case of the composites, DMAPAAQ $+\mathrm{FeOOH}$ and $\mathrm{DMAA}+\mathrm{FeOOH}$, additionally, $\mathrm{FeCl}_{3}$ and $\mathrm{NaOH}$ were added to impregnate the iron components in the polymer gel structure [4-6].

\subsection{Adsorption Experiment}

To perform the Mn adsorption experiment, $20 \mathrm{mg}$ of dried gel composite $(\gamma-\mathrm{FeOOH}$, DMAPAAQ, DMAPAAQ + FeOOH, DMAA, and DMAA + FeOOH) was added in $40 \mathrm{~mL}$ of Mn or As a solution in a small beaker and was kept in the stirrer at $200 \mathrm{rpm}$ rotation, at $20{ }^{\circ} \mathrm{C}$ for $24 \mathrm{~h}$. Following this, a $30 \mathrm{~mL}$ sample was collected using a syringe. The remaining amount of Mn present in the solution was measured by ICP-MS. The amount of adsorption of Mn was measured by Equation (1).

$$
\mathrm{Q}=\left[\left(\mathrm{C}_{0}-\mathrm{C}_{\mathrm{v}}\right) \times \mathrm{V}\right] / \mathrm{m}
$$


where, Q: amount of adsorption (mol/g), $\mathrm{C}_{0}$ : initial concentration $(\mathrm{mol} / \mathrm{L}), \mathrm{C}_{\mathrm{v}}$ : equilibrium concentration (mol/L), V: quantity of solution $(\mathrm{L})$, m: mass of the adsorbent $(\mathrm{g})$.

\section{Results and Discussion}

\subsection{Adsorption of Mn by the Cationic Gel and Cationic Gel Composite}

To examine the efficiency of the removal of Mn using the cationic gel and cationic gel composite, we experimented with the amount of adsorption of Mn using both the DMAPAAQ + FeOOH gel and DMAPAAQ gel. Figure 1 shows the adsorption amount increased when we increased the concentration of the Mn solution when DMAPAAQ + FeOOH gel was used. Similarly, in the case of DMAPAAQ gel, the adsorption amount of $\mathrm{Mn}$ also increased with the increasing Mn concentration. However, the adsorption amount of Mn was higher in the case of DMAPAAQ + FeOOH than that of DMAPAAQ, when the initial concentration of $\mathrm{MnSO}_{4}$ was more than $25 \mathrm{mg} / \mathrm{L}$. DMAPAAQ + FeOOH gel composite contains $62.1 \mathrm{wt} \%$ of $\gamma$-FeOOH contents in its gel structure [6], which increased Mn adsorption. Figure 2a shows that the adsorption of Mn using DMAPAAQ + $\mathrm{FeOOH}$ gel follows the Freundlich isotherm smoothly as the $\mathrm{R}^{2}$ value is 0.9 . Figure $2 b$ shows that the adsorption of Mn using DMAPAAQ + FeOOH gel follows the Langmuir isotherm smoothly as the $\mathrm{R}^{2}$ value is 0.92 . Therefore, the adsorption of Mn by DMAPAAQ $+\mathrm{FeOOH}$ fits best with Langmuir isotherm. Hence, the type of adsorption was chemisorption. Therefore, ionic or covalent chemical bonds are formed between the adsorbent (DMAPAAQ + FeOOH) and the adsorbate (Mn) [7]. The methyl groups adhered to the amino group in the structure of DMAPAAQ binds with the sulfate through ionic interactions. The sulfate ions also tie-up with $\mathrm{Mn}^{2+}$. As a result, the cationic gel, DMAPAAQ, can adsorb Mn, despite Mn being a cation.

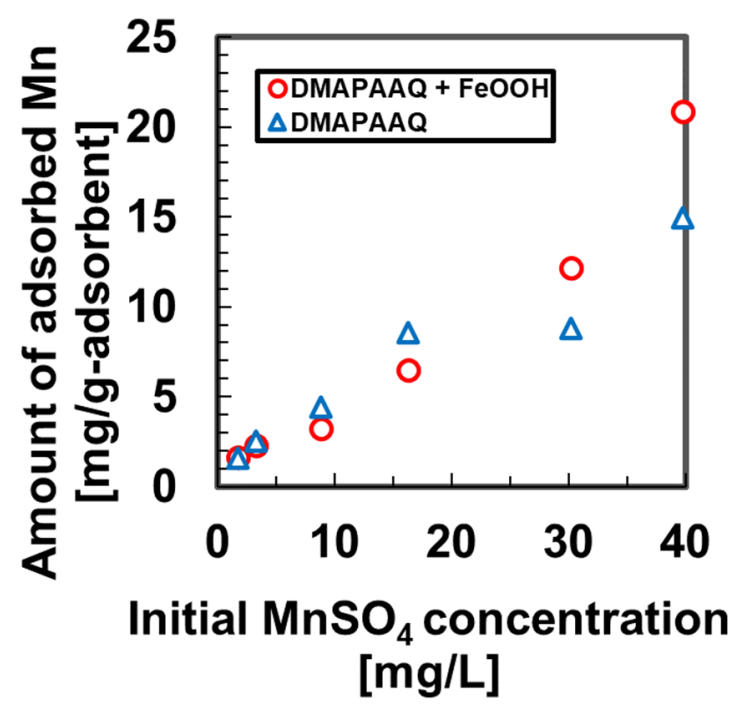

Figure 1. Amount of adsorption of Mn by DMAPAAQ gel and DMAPAAQ + FeOOH gel composite at different initial $\mathrm{MnSO}_{4}$ concentrations. 


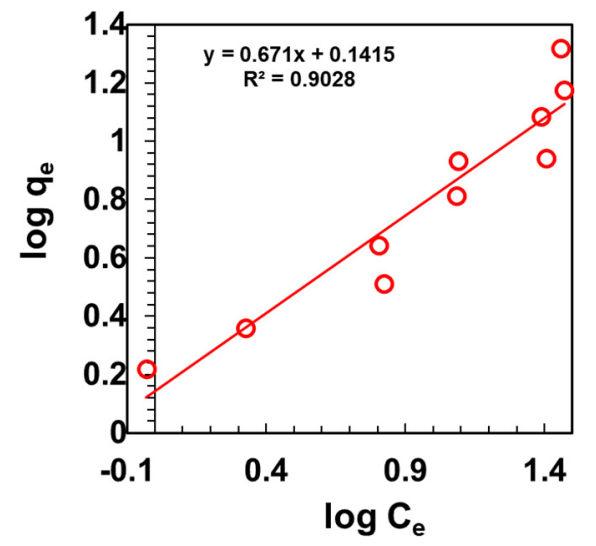

(a)

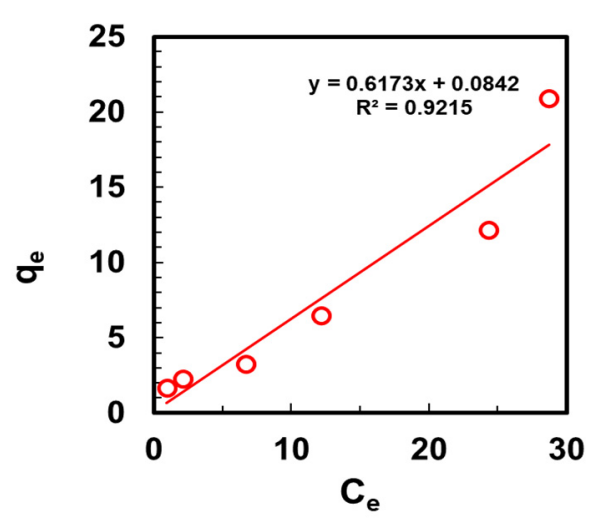

(b)

Figure 2. Adsorption isotherms when Mn was adsorbed by DMAPAAQ + FeOOH gel composite: (a) Freundlich isotherm; (b) Langmuir isotherm.

\subsection{Comparative Adsorption of Mn by Non-Ionic Gel, Non-Ionic Gel Composite, and $\gamma-\mathrm{FeOOH}$}

To further understand how $\gamma$-FeOOH increased the adsorption, when it was impregnated into the polymer gel structure and also to evaluate the advantage of cationic gels over the non-ionic gels, we experimented with the amount of adsorption of Mn using the $\mathrm{DMAA}+\mathrm{FeOOH}$ gel and DMAA gels and also $\gamma$-FeOOH. Figure 3 shows that in the case of DMAA gel, the adsorption of Mn was nearly zero or no adsorption. In the case of $\mathrm{DMAA}+\mathrm{FeOOH}$ gel, the adsorption amount was slightly higher than that of DMAA gel, but still, the amount was very low. However, in the case of $\gamma$-FeOOH, the adsorption of Mn was achieved, and it increased with the increase in the initial concentration of the $\mathrm{MnSO}_{4}$ solution.

The thermogravimetric analysis of DMAA + FeOOH gel suggests that the amount of $\mathrm{FeOOH}$ in the structure of the gel was $51.3 \mathrm{wt} \%$. The adsorbed amount of Mn by DMAA $+\mathrm{FeOOH}, \gamma-\mathrm{FeOOH}$, and DMAA gel were $0.78,2.4$, and $0 \mathrm{mg} / \mathrm{g}$ respectively. Hence, the $51.3 \mathrm{wt} \%$ of $\gamma$-FeOOH particles alone contributed to the DMAA + FeOOH gel composite being able to adsorb $\mathrm{Mn}$. Similarly, $\gamma$-FeOOH particles improved the amount of adsorption of Mn in DMAPAAQ + FeOOH gel composite because we observed an increase in Mn adsorption from 14.96 to $20.89 \mathrm{mg} / \mathrm{g}$ when DMAPAAQ gel was impregnated with $\gamma$ $\mathrm{FeOOH}$ because the presence of $\gamma-\mathrm{FeOOH}$ particles in the polymer structure was advantageous to remove harmful components as those $\gamma$-FeOOH particles were favorable for the adherence of the harmful components in the polymer binding sites [6]. However, when the concentration of $\mathrm{Mn}$ was less than $25 \mathrm{mg} / \mathrm{L}$, the effect of $\gamma$ - $\mathrm{FeOOH}$ in improving the Mn adsorption amount was less in the case of DMAPAAQ + FeOOH and DMAA + $\mathrm{FeOOH}$ because at the Mn concentration lower than $25 \mathrm{mg} / \mathrm{L}$, Mn components could not be strongly adhered to the adsorption sites of the polymer structure. Therefore, the removal of Mn was possible when the cationic gel and non-ionic gel was impregnated with $\gamma$-FeOOH at natural water conditions. 


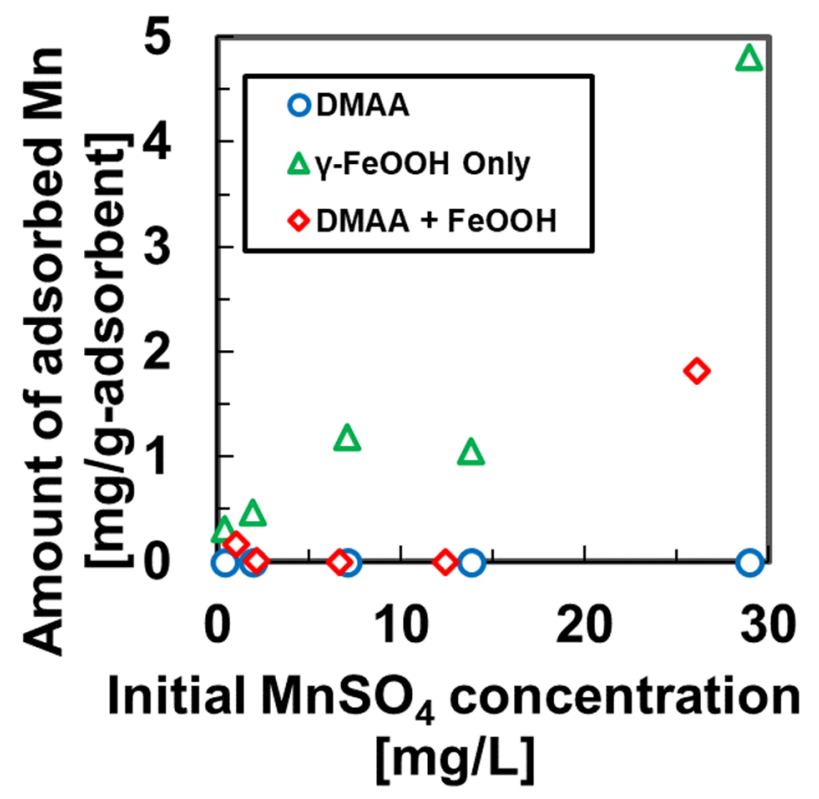

Figure 3. Amount of adsorption of Mn by DMAA gel, $\gamma-\mathrm{FeOOH}$, and DMAPAAQ + FeOOH gel composite at different initial $\mathrm{MnSO}_{4}$ concentrations.

\subsection{Simultaneous Adsorption of $\mathrm{Mn}$ and As}

Previously, $\gamma$-FeOOH was proved to be effective in removing As $[6,8,9]$ and $\mathrm{Mn}[10]$, but discretely. The effectiveness of $\gamma-\mathrm{FeOOH}$ in simultaneous removal of As and $\mathrm{Mn}$ was not studied before because simultaneous removal of cation and anion by the same adsorbent could not be achieved. Hence, for the first time, we also examined the simultaneous adsorption of $\mathrm{Mn}$ and As and the adsorption of $\mathrm{Mn}$ in the presence of As (V) and As (III) solutions (Figure 4), as well as the adsorption of both As (V) and As (III) in the presence of Mn solution using DMAPAAQ + FeOOH gel composite (Figure 5).

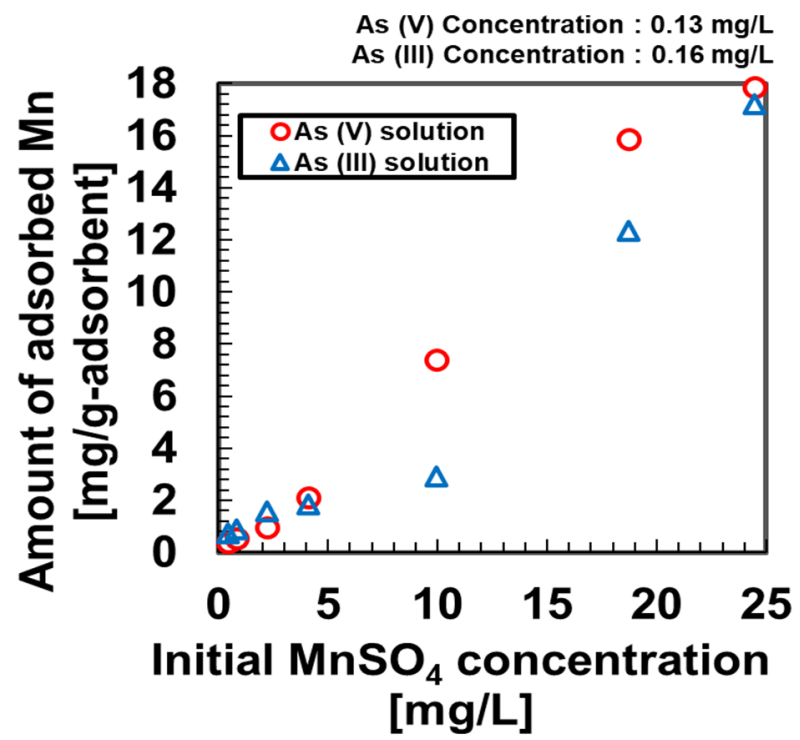

Figure 4. Adsorption of Mn by DMAPAAQ gel and DMAPAAQ + FeOOH gel composites in the presence of $\mathrm{As}(\mathrm{III})$ and $\mathrm{As}(\mathrm{V})$ solutions.

In Figure 4, the adsorption of Mn in the solution of As (V), As (III) was examined. The adsorbent was DMAPAAQ + FeOOH. The concentrations of As (III) and As (V) solutions were 0.16 and $0.13 \mathrm{mg} / \mathrm{L}$, respectively. We conducted our experiment with low As 
concentrations because at high As concentrations, precipitations formed. Hence, the actual adsorption amount of Mn or As could not be obtained. However, at the concentrations of As, at which we conducted our experiment, no precipitations were formed. Figure 4 shows that the adsorption of Mn had almost no deviation due to the presence of arsenic when the results were compared with the values of Mn adsorption with the same adsorbent when As was not added in the solution (Figure 1).

Moreover, from Figure 5, we found that the adsorption of As (V) and As (III) adsorption remained almost constant even after the presence of Mn solution. Figure 5 suggests that when the initial $\mathrm{MnSO}_{4}$ was lower, the amount of adsorption of As (V) was almost like that of the samples where the initial amount of $\mathrm{MnSO}_{4}$ was higher. A similar phenomenon was adsorbed when the adsorption of As (III) was studied in the presence of increasing Mn concentrations. The adsorption of As (III) almost remained constant despite the variation in the concentration of Mn solution. This was possible because As and Mn did not compete for being adhered to the adsorption sites in the structure of the adsorbents and the adsorption sites could accommodate both As and Mn simultaneously. The reason is As exchanged ion to the amino group of the polymer structure of DMAPAAQ and Mn was connected to $\gamma$-FeOOH.

The removal of As (V) was higher than that of As (III). Removing As (III) is harder than As (V) [11] because, at neutral pH levels, adsorption processes are not effective on uncharged forms of As(III) [12]. Moreover, at neural pH levels, As (III) cannot be ionized. On the other hand, As (V) is ionized at $\mathrm{pH}$ 7. These results prove that As and Mn can be effectively removed or adsorbed with the DMAPAAQ + FeOOH gel composite.

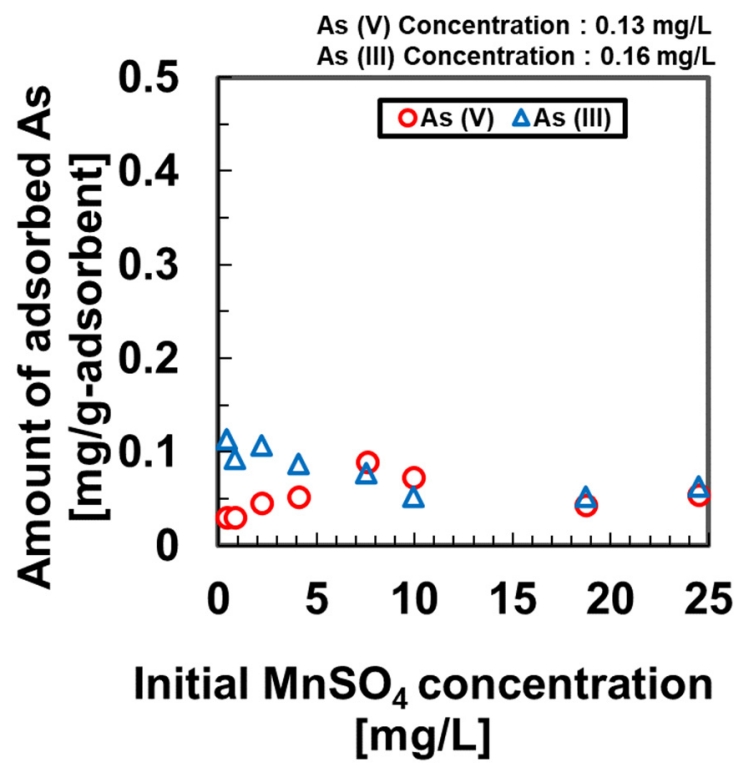

Figure 5. Adsorption of As (III) and As (V) by DMAPAAQ gel and DMAPAAQ + FeOOH gel composites in the presence of different concentrations of Mn.

\section{Conclusions}

In conclusion, Mn could be effectively removed by DMAPAAQ gel, DMAPAAQ + FeOOH gel composite, DMAA + FeOOH gel composite, and $\gamma-\mathrm{FeOOH}$ at the natural water conditions. The highest amount of adsorption of Mn which could be achieved was $20.89 \mathrm{mg} / \mathrm{g}$ by DMAPAAQ + FeOOH gel composite. The reason was the components of $\gamma-$ $\mathrm{FeOOH}$ in the polymer structure of DMAPAAQ + FeOOH helped to increase its efficiency in removing $\mathrm{Mn}$, just like $\gamma$-FeOOH helped DMAA $+\mathrm{FeOOH}$ to achieve the adsorption of Mn performance.

Lastly, for the first time, we performed the study of simultaneous adsorption of As and Mn. We concluded that both As and Mn could be removed simultaneously when 
DMAPAAQ + FeOOH, without the removal performance having any effect because As was adhered to the amino group in the polymer structure of DMAPAAQ and Mn was attached to $\gamma$-FeOOH. Lastly, As (V) is adsorbed more than As (III) because at the neutral $\mathrm{pH}$ level, it is not possible for As (III) to be ionized. However, As (V) can be ionized at pH 7. In the future, further study is required as these results need to be compared with anionic gel and anionic gel composites and other green polymer adsorbents. Our aim is to remove the harmful metal components such as $\mathrm{As}, \mathrm{Mn}, \mathrm{Cr}, \mathrm{Cd}$, and other components simultaneously.

Author Contributions: Conceptualization, S.R.S.; methodology, S.R.S.; software, S.R.S.; validation, S.R.S. and T.G.; formal analysis, S.R.S.; investigation, S.R.S.; resources, T.G.; data curation, S.R.S.; writing - original draft preparation, S.R.S.; writing - review and editing, T.G.; visualization, S.R.S.; supervision, T.G.; project administration, T.G.; funding acquisition, S.R.S. All authors have read and agreed to the published version of the manuscript.

Funding: This research was funded by the Japan Society for the Promotion of Science (JSPS), KAKENHI grant number 19J22780. The APC was funded by JSPS KAKENHI grant number 19J22780.

Institutional Review Board Statement: Not applicable.

Informed Consent Statement: Not applicable.

Data Availability Statement: The data presented in this study are available in article.

Acknowledgments: One of the authors, S.R.S., is the Research Fellow (DC1) of the JSPS.

Conflicts of Interest: The authors declare no conflict of interest. The funders had no role in the design of the study; in the collection, analyses, or interpretation of data; in the writing of the manuscript, or in the decision to publish the results.

\section{References}

1. Frisbie, S.H.; Ortega, R.; Maynard, D.M.; Sarkar, B. The concentrations of arsenic and other toxic elements in Bangladesh's drinking water. Environ. Health Perspect 2002, 110, 1147-1153.

2. Sarkar, A.M.; Rahman, A.K.M.L.; Samad, A.; Bhowmick, A.C.; Islam, J.B. Surface and Ground Water Pollution in Bangladesh: A Review. Asian Rev. Environ. Earth Sci. 2019, 6, 47-69, doi:10.20448/journal.506.2019.61.47.69.

3. Verlicchi, P.; Grillini, V. Surface and Groundwater Quality in South African Area-Analysis of the Most Critical Pollutants for Drinking Purposes. Proceedings 2019, 48, 3, doi:10.3390/ECWS-4-06430.

4. Safi, S.R.; Gotoh, T.; Iizawa, T.; Nakai, S. Development and regeneration of composite of cationic gel and iron hydroxide for adsorbing arsenic from ground water. Chemosphere 2019, 217, 808-815, doi:10.1016/j.chemosphere.2018.11.050.

5. Safi, S.R.; Gotoh, T.; Iizawa, T.; Nakai, S. Removal of Arsenic Using a Cationic Polymer Gel Impregnated with Iron Hydroxide. J. Vis. Exp. 2019, e59728, doi:10.3791/59728.

6. Safi, S.R.; Senmoto, K.; Gotoh, T.; Iizawa, T.; Nakai, S. The effect of $\gamma$-FeOOH on enhancing arsenic adsorption from groundwater with DMAPAAQ + FeOOH gel composite. Sci. Rep. 2019, 9, 11909, doi:10.1038/s41598-019-48233-x.

7. Langmuir Adsorption-An Overview I ScienceDirect Topics. Available online: https://www.sciencedirect.com/topics/engineering/langmuir-adsorption (accessed on 20 October 2020).

8. Repo, E.; Mäkinen, M.; Rengaraj, S.; Natarajan, G.; Bhatnagar, A.; Sillanpää, M. Lepidocrocite and its heat-treated forms as effective arsenic adsorbents in aqueous medium. Chem. Eng. J. 2012, 180, 159-169, doi:10.1016/j.cej.2011.11.030.

9. Lin, S.; Yang, H.; Na, Z.; Lin, K. A novel biodegradable arsenic adsorbent by immobilization of iron oxyhydroxide (FeOOH) on the root powder of long-root Eichhornia crassipes. Chemosphere 2018, 192, 258-266, doi:10.1016/j.chemosphere.2017.10.163.

10. Sung, W.; Morgan, J.J. Oxidative removal of Mn(II) from solution catalysed by the $\gamma$-FeOOH (lepidocrocite) surface. Geochim. Cosmochim. Acta 1981, 45, 2377-2383, doi:10.1016/0016-7037(81)90091-0.

11. Deng, Y.; Li, Y.; Li, X.; Sun, Y.; Ma, J.; Lei, M.; Weng, L. Influence of calcium and phosphate on pH dependency of arsenite and arsenate adsorption to goethite. Chemosphere 2018, 199, 617-624, doi:10.1016/j.chemosphere.2018.02.018.

12. Zhu, N.; Yan, T.; Qiao, J.; Cao, H. Adsorption of arsenic, phosphorus and chromium by bismuth impregnated biochar: Adsorption mechanism and depleted adsorbent utilization. Chemosphere 2016, 164, 32-40, doi:10.1016/j.chemosphere.2016.08.036. 